"TRYING to pour a water-butt through a bootlace" was how one Services officer described pre-satellite longdistance communications for defence. That was in 1969 when Britain first adopted a satellite-borne defence communications system-Skynet-for its own exclusive and interference-free use, making Hong Kong and ships at sea (in the Gulf of Carpentaria for example) as instantly accessible as Aldershot from Whitehall. Although the satellite itself, Skynet I, was built (to a tight $£ 6$ million contract) by PhilcoFord in America, the hard-headed specification was British and the groundbased terminals to communicate with it were British-designed and built. The Skynet system must rank as the most enterprising and successful British space venture yet achieved with several world 'firsts' to its credit. It was the first operational defence system to use a geostationary satellite; and, the $3 \frac{1}{2}$ foot shipboard terminal, Scot, remains the smallest and most ingenious 'earthstation' for satellite communications yet developed, and the envy of the US Navy.

The original Skynet satellite (Skynet I) has now exceeded its planned operational life and is due for replacement. To ensure continuous operation in all circumstances the original satellite, poised over the Indian Ocean, was duplicated. The second could act as standby if the first developed faults; otherwise it could provide additional capacity in an emergency. In the event only one of the Skynet I series ever became operational. In its companion the solid fuel packing of the centrally situated apogee motor had an undetected crack which caused the motor to explode on ignition, effectively disposing of the satellite at the same time. It seems that the single Skynet I in orbit managed to sustain its role without a standby.

\section{Plugging the hole in Skynet}

from Angela Croome

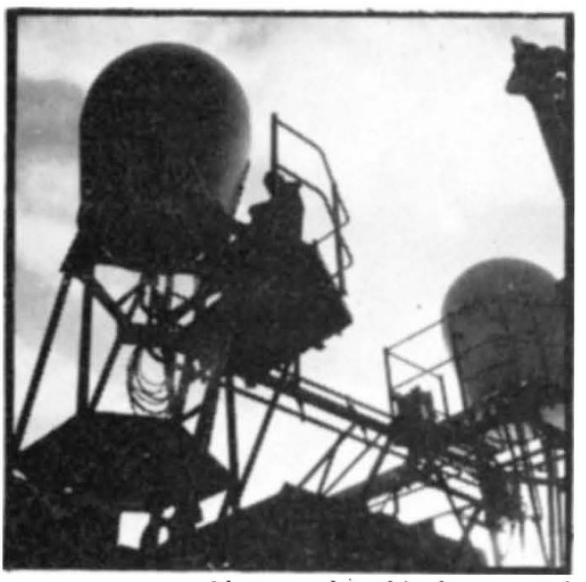

Skynet: the ship-borne end

Last January the first of two replacements was launched by Thor-Delta from Cape Canaveral. It too came to grief so now there is the prospect of the second, Skynet II, phase of the system, also operating with a single satellite despite $100 \%$ planned redundancy. On this occasion the second stage of the launch rocket misfunctioned in the sense that the jets of the motor jammed hard over while firing, causing the vehicle to corkscrew wildly and subjecting the satellite to forces greatly exceeding those allowed for in the design specification. The satellite was 'missing presumed lost' for three days but was then picked up by a United States Air Force tracking station over the Pacific. It was still functional and responding to interrogation and commands but in a hopelessly low orbit. An attempt to 'kick' the satellite out to an orbit clear of the Earth's atmosphere with the onboard apogee motor failed. Nonetheless the
British contractors, Marconi Space and Defence Systems Ltd, were well pleased with how well the spacecraft had stood up to its very rough passage.

In the last week of August the standby Skynet II was dispatched to the United States in readiness for launch in November to take over Britain's overseas defence communications role for a further three years. The overall design and engineering concept of Skynet II is similar to Skynet I; it may be considered a 'stretched' Skynet I. It is about a third larger than its predecessor, however, and has a considerably greater communications capacity. The ease, convenience and immediacy of 'voice-contact-by-satellite' has, not surprisingly, proved popular with the Ministry of Defence, as transatlantic businessmen similarly welcomed the coming of Intelsat.

Demand for faster telecommunications grows with supply. This has become a truism in the world of commercial telecommunications. Predictions of the growth of phone traffic and especially overseas phone traffic are always too low. No doubt the same can be said of defence communications. It is not difficult to imagine the asset that Skynet must have been and still is to the British bases in Cyprus during the recent emergency. Yet the future of Skynet is hazy. No decision has yet been made on a backup for Skynet II, although the end of its planned life is not so far off. Defence planning-where a new weapons system for instance takes ten to twenty years to develop-has long made nonsense of five-yearly changes in Government. Can anything so fundamental to the total defence operation as communications, be left to the shifts of party politics? While Britain continues to have overseas defence commitments, a return to "bootlace" communications would be a false economy.

\section{Life sentence}

Av astronomical surprise for dilettantes and professionals alike was provided by Sir Bernard Lovell during a discussion at the BA meeting. He delivered a severe body blow to the popular notion that there may be around 100,000 technolog "? civilisations in our Galaxy.

In the past, Sir Bernard said, one extremely important factor had been omitted from the calculations. Nobody had yet taken account of the fact that at least $90 \%$ of the 100,000 million stars in the Galaxy are $K$ or $M$ stars, which exhibit characteristics that could well preclude the development of organic life in their vicinity. For a start, they only exist for about 10 to
100 million years before becoming black dwarf stars.

It is extremely unlikely that these stars could develop a solar system in so short a time, and in any case that hardly seems long enough to allow for the evolution of an advanced civilisation. Which is just as well really, because any organic life which might evolve would find itself in an extremely inhospitable environment.

Sir Bernard explained that $\mathrm{K}$ and $\mathrm{M}$ stars have extraordinary flare properties: blasts often last for periods of up to several hours, during which the normal intensity of emission doubles. The radiation effects would of course be quite lethal to most complicated life forms.
- Because of an error in transmission, Nature's account of the recent NAS statement on plasmid engineering contained an inaccuracy which might have caused a misunderstanding about the moratorium. Under the heading of types of research which should be halted, we listed "autonomously replicating bacterial plasmids that might result in the introduction of genetic determinants for antibiotic resistance or bacterial toxin formation into bacterial strains that do not presently carry such determinants..." This should have read: "Construction of new autonomously replicating bacterial plasmids . . ." etc. We regret any inconvenience this error might have caused. 